\title{
Los Smithsons en Golden Lane: la Simultaneidad de Hechos en el Fotomontaje como Construcción de lo Real
}

\section{The Smithsons at Golden Lane: The Simultaneity of Events within the Photomontage as Construction of The Real}

Iván CAPDEVILA CASTELLANOS

Universidad de Alicante.

capdevila@ua.es

\section{Vicente IBORRA PALLARÉS}

Universidad de Alicante

vicente.iborra@ua.es

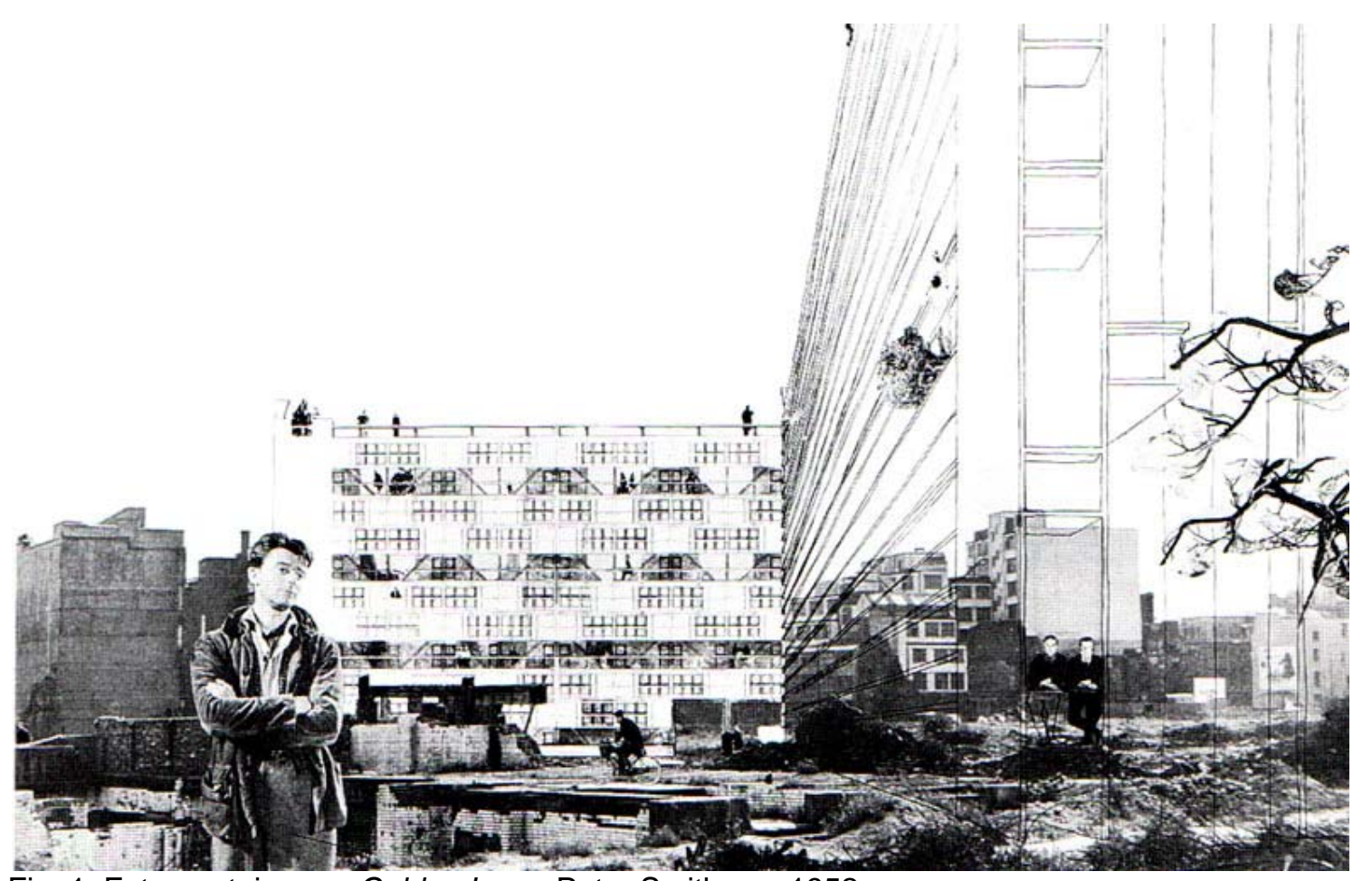

Fig. 1. Fotomontaje para Golden Lane. Peter Smithson, 1952 
$\left[I^{2}\right]$ Innovación e Investigación en Arquitectura y Territorio. Revista Científica.

\section{Resumen}

El uso innovador de la técnica del fotomontaje en la propuesta de concurso para Golden Lane en 1952 por parte de los Smithsons, como estrategia de celebración de lo ordinario en un East End londinense de posguerra física y psicológicamente destruido, les permitirá descubrir su fuente de inspiración en la realidad "tal cual" es, para convertirla en un nuevo paradigma arquitectónico.

\section{Palabras Clave}

Smithsons, fotomontaje, realidad, paradigma

\section{Abstract}

The innovative use of the photomontage technique in the competition proposal for Golden Lane in 1952 by the Smithsons, as strategy of celebration of the ordinary within a physically and psychologically destroyed postwar London's East End, will allow them to discover its inspirational source in reality "as found" and to turn it into a new architectural paradigm.

\section{Keywords}

Smithsons, photomontage, reality, paradigm 
$\left[1^{2}\right]$ Innovación e Investigación en Arquitectura y Territorio. Revista Científica.

\section{1. ¿POR QUÉ GOLDEN LANE?}

Golden Lane era uno de esos lugares donde las huellas de la Segunda Guerra Mundial seguían presentes y donde se convocó un concurso de vivienda social siguiendo el County of London Plan de 1943.

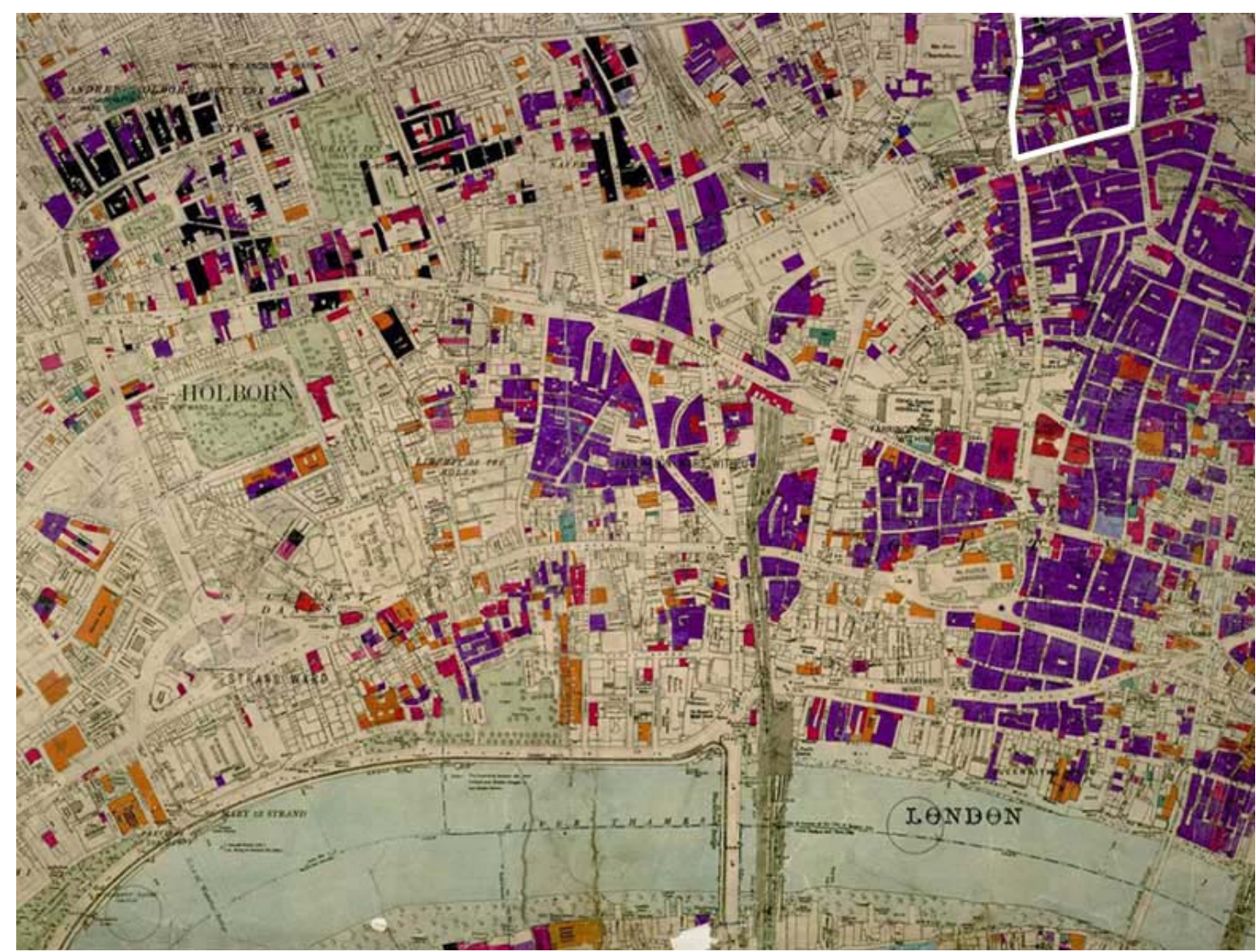

Fig. 2. Plano de trabajo de Patrick Abercrombie. Rodeadas por la línea blanca, las edificaciones que estaban antes de la guerra en el solar de Golden Lane.

Golden Lane representaba una oportunidad. Era el momento de posicionarse con respecto a la política de reconstrucción que el Partido Laborista había emprendido para consolidar el Estado del Bienestar.

Golden Lane fue un concurso que Alison y Peter Smithson no ganaron. Tampoco obtuvieron premio alguno. Sin embargo, su propuesta se convertiría en protagonista un año después cuando presentaron los dibujos -junto a 10 fotografías de niños jugando tomadas por Nigel Henderson desde su casa en el número 46 de Chisenhale Road - en el CIAM IX. Su lema Urban Re-Identification era una crítica implícita al funcionalismo que la Carta de Atenas había propugnado para la construcción de nuestras ciudades. 


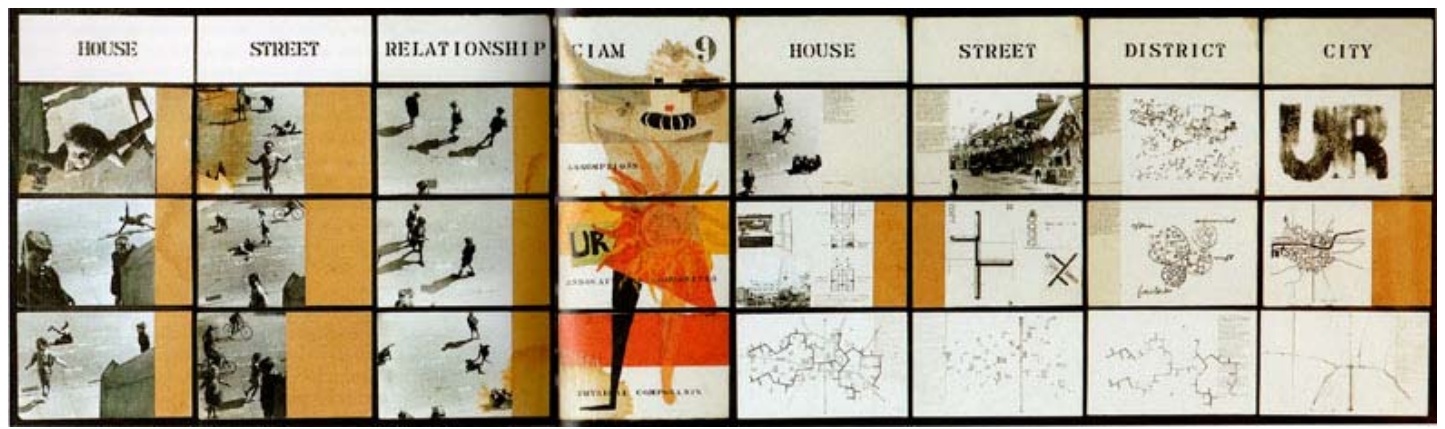

Fig. 3. A+P Smithson. Urban Re-Identification, 1953.

\section{2. ¿QUÉ HAY DE NUEVO EN GOLDEN LANE?}

Uno de los rasgos que dotan a este fotomontaje de algo nuevo es que la fuerza de la imagen reside en la escena representada y no en el objeto diseñado.

El uso del fotomontaje, en sí, no es nada nuevo por entonces: en el mundo de la fotografía se venía utilizando casi desde su invención en 1839 para evocar imágenes surrealistas. Desde principios de siglo XX, las vanguardias artísticas lo habían venido utilizando. Podríamos destacar los trabajos del grupo Dada y de Lazlo Moholy-Nagy en la Bauhaus. También podríamos hablar de su extendido uso en la cartelería cinematográfica o la propaganda política. Tampoco podemos obviar el mundo de la publicidad. Sin embargo este es, en todo caso, un campo tan extenso y diverso que no puede ser más que objeto de reseña en este artículo.

En ese sentido, debemos señalar en el mundo concreto de la arquitectura al alemán Mies van der Rohe que, bajo la influencia de Lilly Reich, destacó notablemente, entre otras cosas, por el uso brillante del fotomontaje como medio de expresión gráfica de sus propuestas. La pertinencia de sus fotomontajes no viene sólo del hecho de su condición de arquitecto sino que son, los propios Smithsons, los que lo sitúan como el principal referente en sus años de formación académica y en los consecuentes primeros años de su práctica profesional. A fuerza de estudiar la obra de Mies, los Smithsons acabaron reproduciendo sus técnicas.

Vemos, por ejemplo, cómo el Collage for a Small Art Museum de Mies y uno de los fotomontajes del Proyecto Final de Carrera de Peter Smithson (fig. 4) comparten el uso de la perspectiva cónica a línea para representar un interior, el sombreado del exterior para diferenciarlo del interior y la inclusión de imágenes fotográficas de elementos artísticos. 

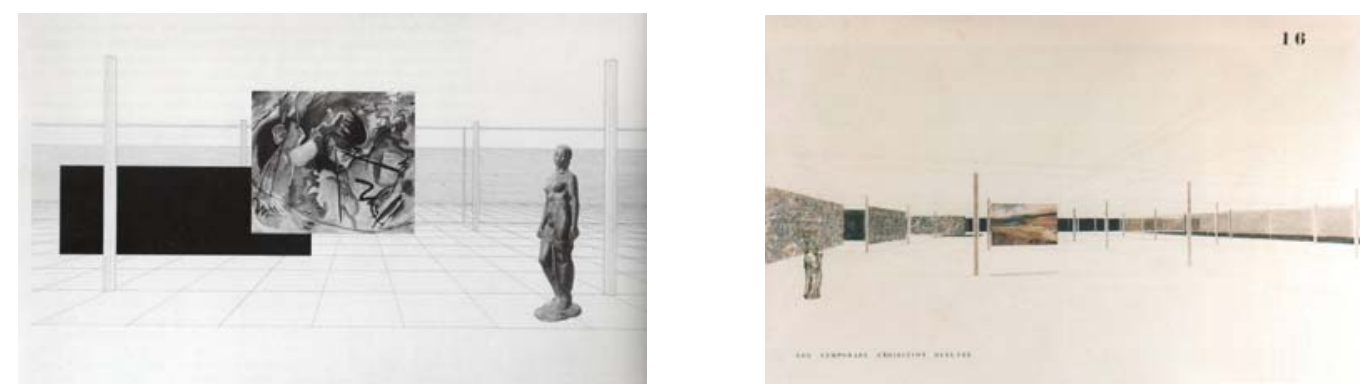

Fig. 4. Collage for a Small Art Museum. Mies van der Rohe, 1941-42. / Imagen en perspectiva de la galería de exposiciones temporales. Proyecto Final de Carrera. Peter Smithson, 1948-49

Aunque Mies utilizó el fotomontaje por primera vez en 1912, su fotomontaje alcanzó cierto virtuosismo en la famosa propuesta para el rascacielos de vidrio en la Friedrichstrasse de Berlín.
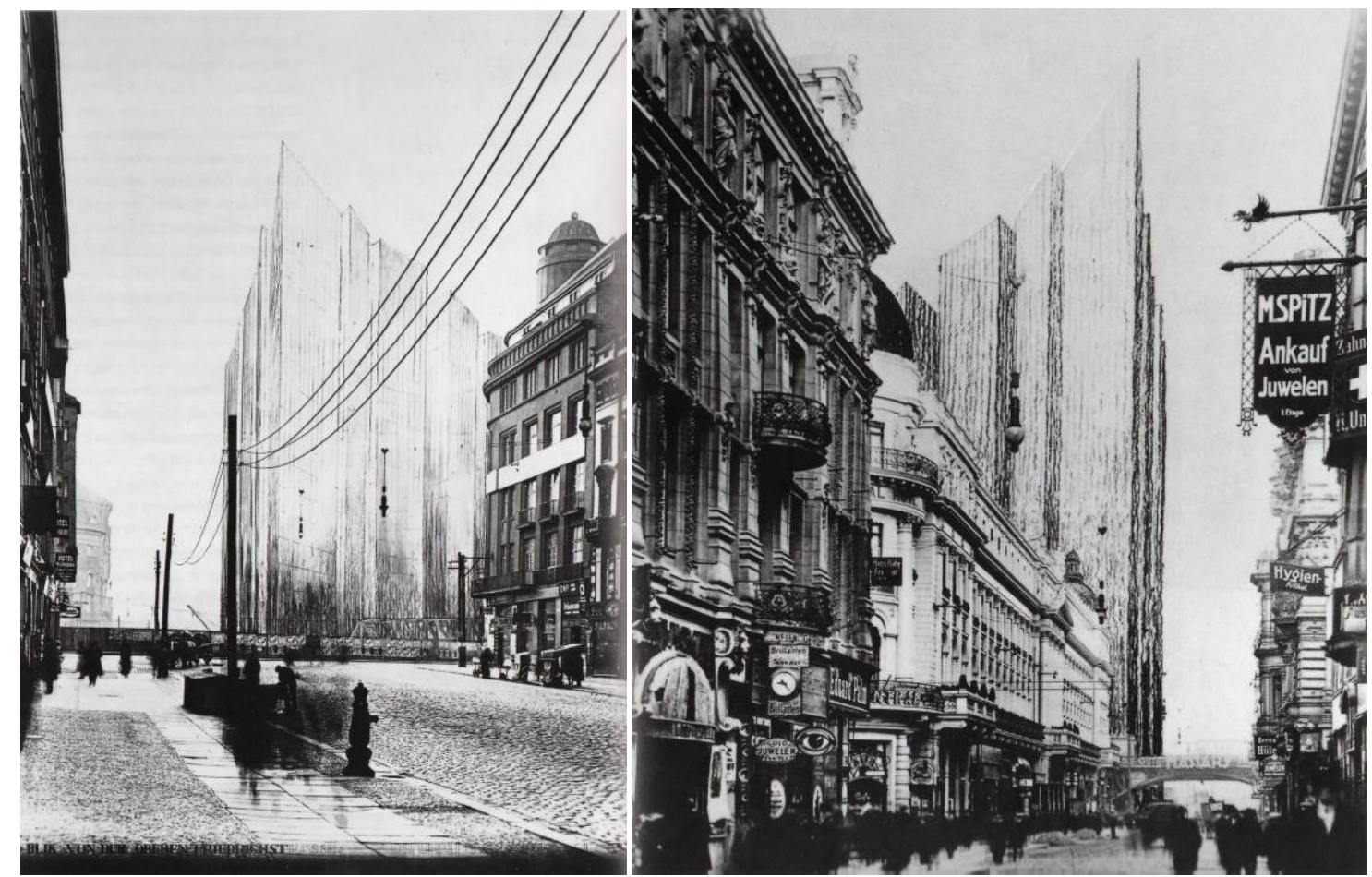

Fig. 5. Concurso para un rascacielos de vidrio en Friedrichstrasse. Mies van der Rohe, 1921-22.

Podemos comprobar que tanto Alison como Peter Smithson, ya en su época de estudiantes, utilizaban esta técnica de combinar fotografías reales con dibujos hechos a mano para dotar de verosimilitud al objeto construido. Objeto y entorno se integraban hasta tal punto que ninguno predominaba en la composición. Se producía la simbiosis perfecta, al menos, visualmente. 


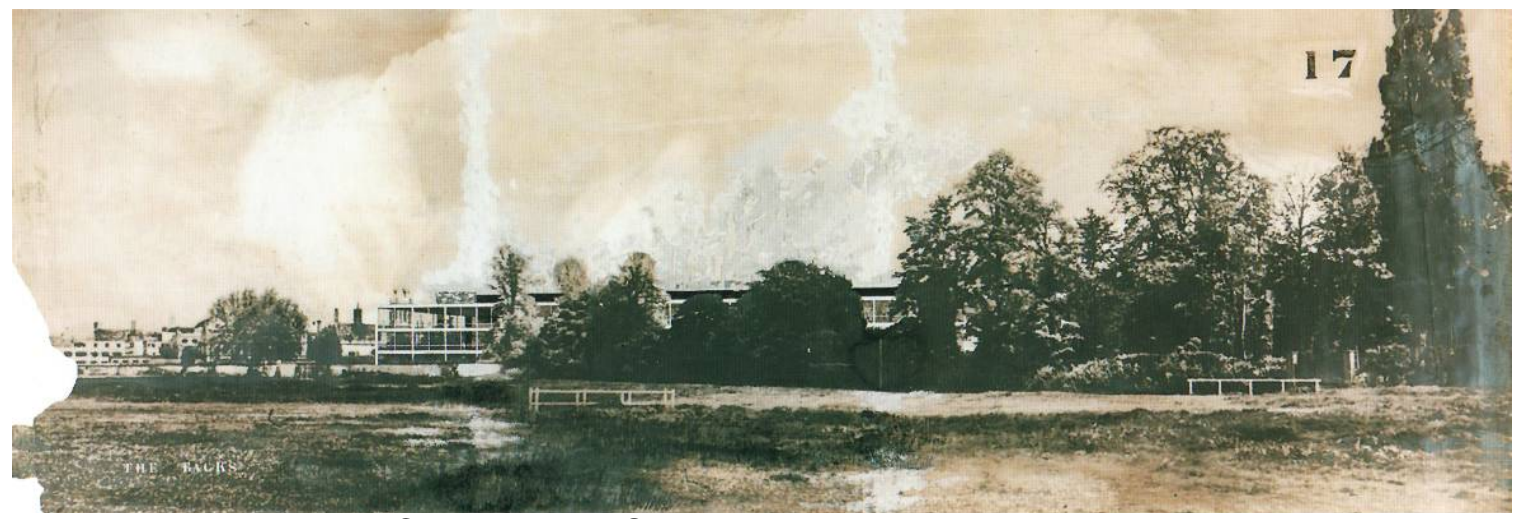

Fig. 6. Proyecto Final de Carrera. Peter Smithson. 1948-49

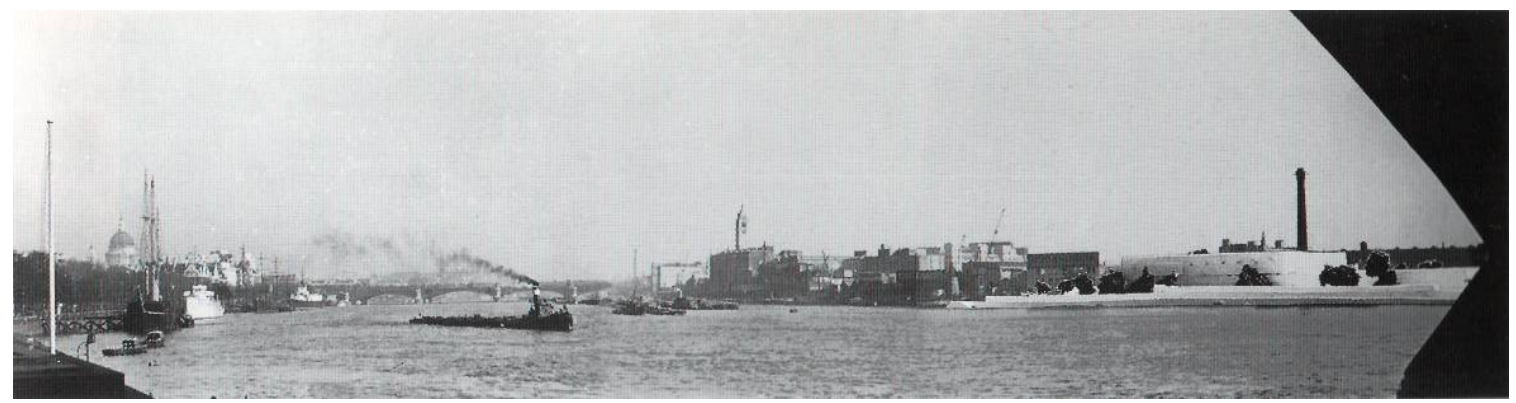

Fig. 7. Proyecto Final de Carrera. Alison Smithson, 1949

Sin embargo, al contrario que Mies, los fotomontajes de los Smithsons previos a Golden Lane están despoblados. Tampoco hay personas en los trabajos de investigación de Peter Smithson sobre lo urbano en sus primeros años en Londres.
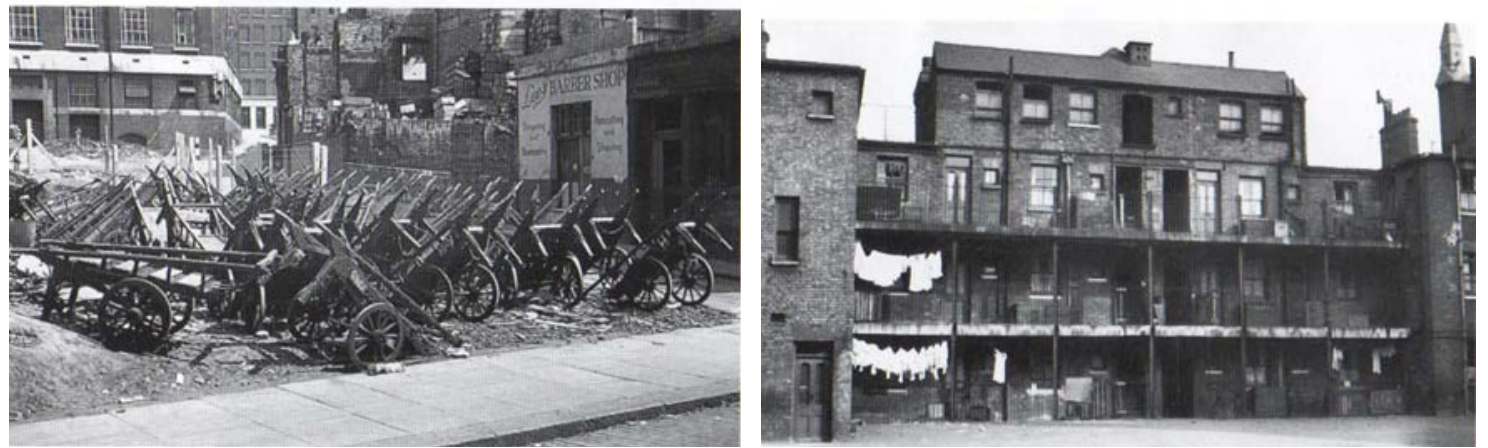

Fig. 8. "Cluster". Cerca de Smithfield. Peter Smithson. 1952. / "Cluster". Cerca de St. George'sin-the-East. Peter Smithson, 1951

Ambas fotografías fueron tomadas durante el tiempo del concurso en zonas bombardeadas del East End londinense. La primera, a escasos metros del solar de concurso.

Así, en Golden Lane observaremos un cambio radical en su corta trayectoria de elaboración de fotomontajes: 
1. No estamos ante una imagen plana. Se pueden diferenciar tres planos distintos: el contexto, las personas y la arquitectura.

2. La referencia directa al contexto: el entorno se muestra "tal cual" es. Deja de ser ese lugar idealizado y perfecto tanto de Mies como de los primeros Smithson.

3. La aparición de las personas. No sólo aparecen por vez primera en sus fotomontajes sino que, en un plano conceptual, lo hacen después de la intervención y con total contundencia, a veces fuera de escala.

4. La arquitectura, casi desmaterializada, queda en un segundo plano o intermedio entre el contexto de la propuesta y las personas que la dotan de vida, a las que cede el protagonismo. Entre ellas, reconocemos a Terence Conran, Jawaharlal Nehru y Gerard Philipe. El hecho de incluir a personas conocidas y populares no es nada casual teniendo en cuenta que Alison coleccionaba anuncios de revistas del momento (algunas eran enviadas directamente por los Eames). Por otro lado, los Smithsons celebrarán poco después la cultura de masas en su artículo "Today We Collect Ads."

Los cuatro fantásticos: ALISON, PETER, EDUARDO Y NIGEL

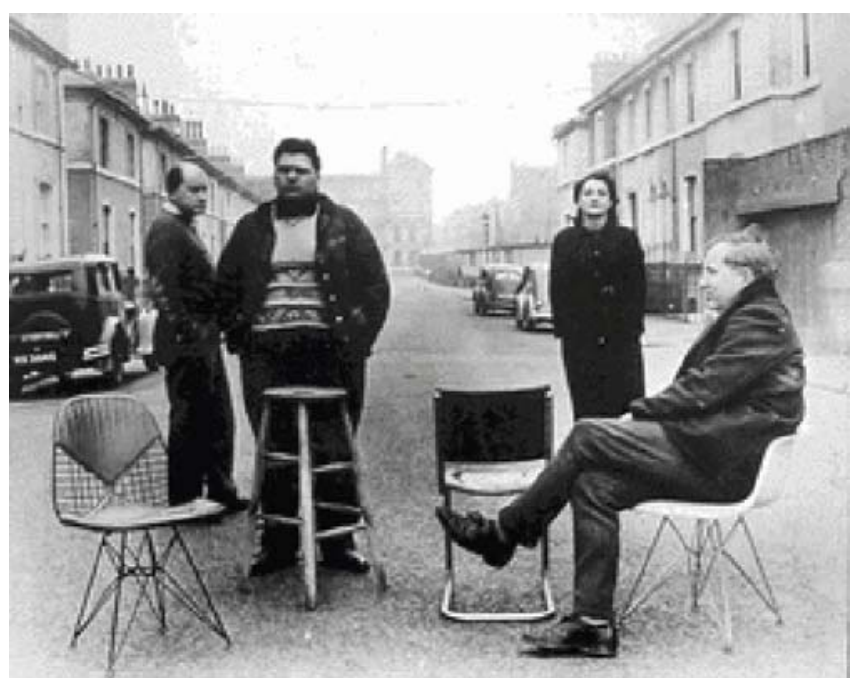

Fig. 9. Limerston Street. Nigel Henderson. 1956

1956, en medio de Limerston Street: Nigel Henderson, Alison y Peter Smithson y Eduardo Paolozzi. Esta foto fue tomada en frente de la casa de los Smithsons y sobre dos sillas de los Eames (dando muestras del vínculo entre ambas parejas) para el catálogo de la exposición This Is Tomorrow.

Se puede decir que los cuatro tenían en común muchas cosas; pero dos, son destacables: la primera, los tres varones fueron profesores de la Central School of Arts; la segunda, el impacto de la guerra.

Los cuatro quedaban semanalmente para intercambiar pensamientos y reforzar las ideas que compartían. Juntos crearon las exposiciones Parallel of Life and Art (1953) en el ICA y Patio and Pavillion (1956) en la Whitechapel Art Gallery, convirtiéndose en parte fundamental del que se conocería como Independent Group.1 
$\left[1^{2}\right]$ Innovación e Investigación en Arquitectura y Territorio. Revista Científica.
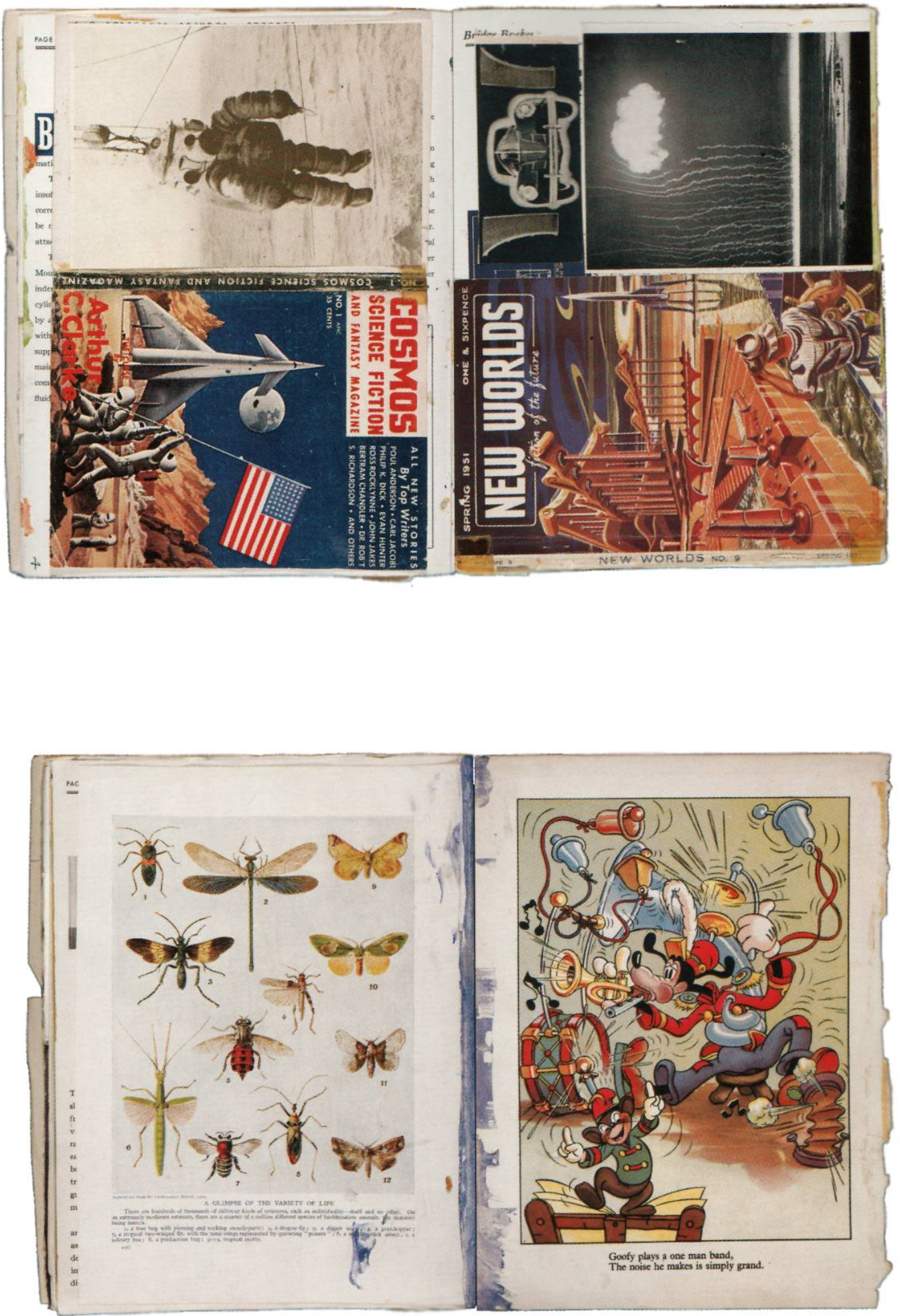

Fig. 10. Scrapbook nº4. Eduardo Paolozzi. 1948 
$\left[I^{2}\right]$ Innovación e Investigación en Arquitectura y Territorio. Revista Científica.

\subsection{Eduardo Paolozzi: El uso del fotomontaje como herramienta creativa}

Sería también en 1952 cuando Eduardo Paolozzi presentaría en el ICA de Londres una serie de imágenes en color sacadas de revistas americanas (Bunk series).

Paolozzi había enseñado a los Smithsons sus collages. Sin embargo, estos realizaban fotomontajes.

Podemos entender el fotomontaje como un tipo particular de collage, en el que sólo se utilizan elementos fotográficos o ilustraciones. Por el contrario, el collage trabaja con materiales brutos, cogidos tal cual. La única manipulación está en la combinación de estos dentro de la obra de arte.

Golden Lane, aún tomando la forma característica de fotomontaje, sufre un desplazamiento hacia la técnica del collage, en el sentido que Alison y Peter Smithson están haciendo un uso creativo del mismo, una interpretación subjetiva. Si bien en los fotomontajes previos tanto de Mies como de los Smithsons no había interpretación subjetiva, en este caso sus autores están especulando sobre un futuro posible desencadenado por la intervención.

Aunque los collages de Paolozzi seguían la tradición de Heartfield, Schwitters y Max Ernst, fue el primero en tomar prestados importantes elementos pictóricos del mundo de la cultura trivial sin un propósito satírico. Paolozzi, por otro lado, reconocería en varias ocasiones la influencia de Dubuffet y su Art Brut. Siguiendo esta filosofía, emplearía una técnica muy poco refinada: la de seleccionar, recortar y pegar al lado de, casi incluso de una manera "poco especializada". Estos materiales provenían de libros y revistas recuperados de zonas bombardeadas. La vivencia personal de Paolozzi de la guerra, en 1944 fue llamado a filas, está detrás de su continua obsesión por la realidad imperfecta. La experiencia posterior de tres años en París le permitió conocer a los más importantes protagonistas del arte moderno así como acceder a las mismas influencias filosóficas que estaban dominando el panorama cultural francés, entre las que destacaban Jean Paul Sartre y Henri Lefebvre. Este último acababa de publicar en 1947 su Critique de la vie quotidienne en la que celebraba la vida en comunidad como un aspecto fundamental de la experiencia del día a día. Por su parte, Jean Paul Sartre, cuya influencia llegaron a reconocer los Smithsons, había publicado en 1946 su influyente ensayo L'existentialisme est un humanisme, en el que situaba al hombre y su subjetividad antes que la razón. Así, la interpretación subjetiva de la realidad y la realidad misma habían sido puestas por Lefebvre y Sartre en el centro de interés de muchos artistas, Paolozzi entre ellos.

Paolozzi mostró a los Smithsons cómo hacer convivir elementos dispares de la realidad en una nueva armonía, gracias al uso creativo del collage y como así lo había aprendido de los artistas surrealistas en París. El arte de "seleccionar, colocar y dar la vuelta" a objetos cotidianos encontrados para generar nuevos significados, al que tanto harán referencia los Smithsons, es la fuerza motriz de Paolozzi, el cual nos descubrió que la intensidad creativa estaba más en el proceso que en el resultado. 
$\left[I^{2}\right]$ Innovación e Investigación en Arquitectura y Territorio. Revista Científica.

La materia prima empleada por Paolozzi estaba en su origen dañada, evidenciando las secuelas de la guerra, lo mismo que el solar de Golden Lane, cuya aparición "tal cual" con los signos de los bombardeos refuerza esta relación. Así nos lo mostraron los Smithsons en su fotomontaje.

\subsection{Nigel Henderson: El contexto importa, la vida aparece}

En 1945 Nigel Henderson se trasladó con su mujer al 46 de Chisenhale Road, distrito de Bethnal Green, Londres. El objetivo de Judith era estudiar de incógnito a la familia Samuels. Ésta vivía en el n³1. La mujer de Nigel lo situó súbitamente en una toma de conciencia por lo social. El estudio de caso que Judith estaba realizando, Discover your Neighbour, era una de las iniciativas del proyecto gubernamental de Mass Observation.

Lo social como tal, estaba entrando a formar parte no sólo de las distintas manifestaciones artísticas sino que la sociología misma estaba perfeccionando desde los años 30 sus armas para definir científicamente la realidad:

"Durante la mayor parte del tiempo en la Slade (1945-49) centré mi actividad en Bethnal Green merodeando por ahí y mirando cosas." (Henderson citado en Walsh 2001, pp. 69)

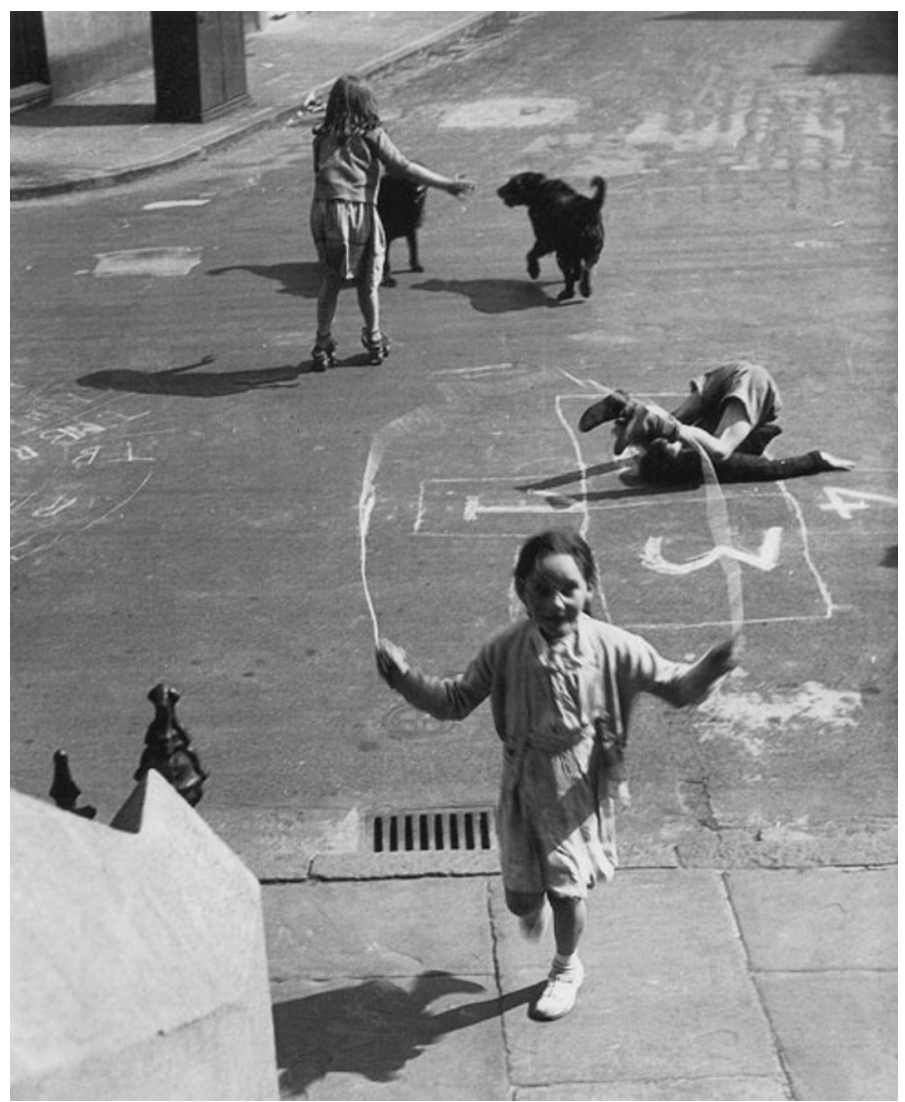

Fig. 11. Gillian Alexander saltando a la comba. Nigel Henderson. 1951 

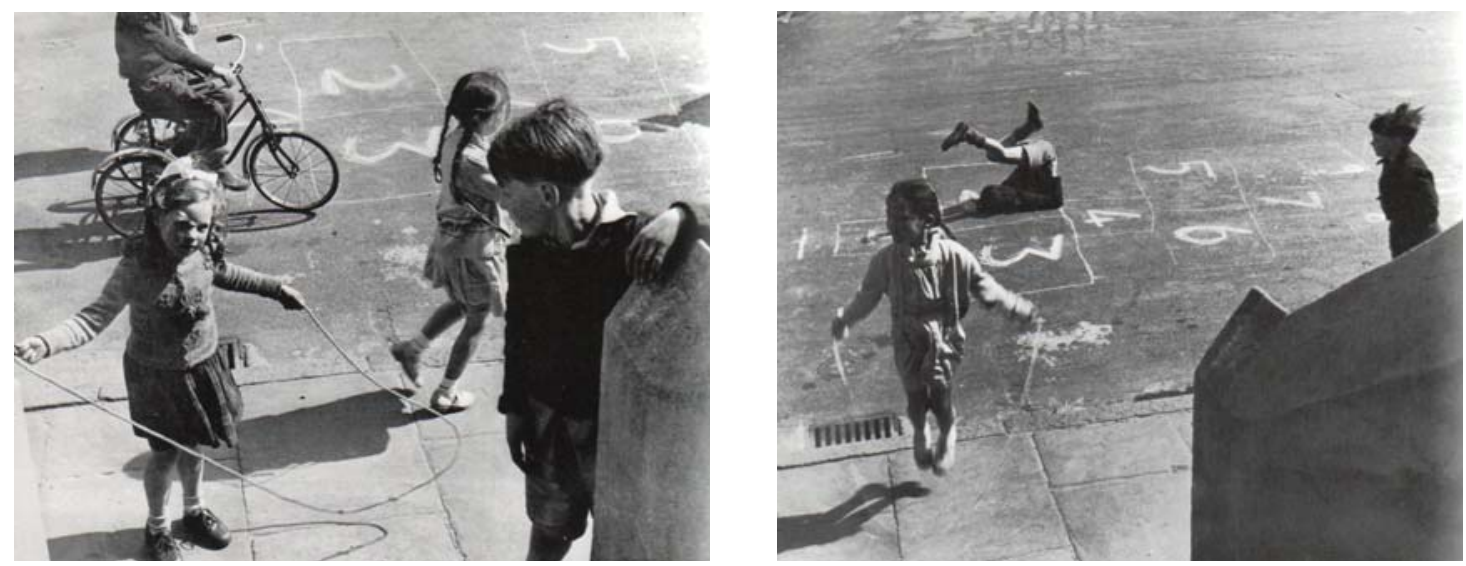

Fig. 12. Chisenhale Road. Nigel Henderson. Entre 1949 y 1952

La tradición de los niños jugando y, en especial, a la rayuela era algo habitual tanto en los textos como en la fotografía social. El trabajo de Humphrey Spender, para Mass Observation en 1937, era conocido por Nigel Henderson.
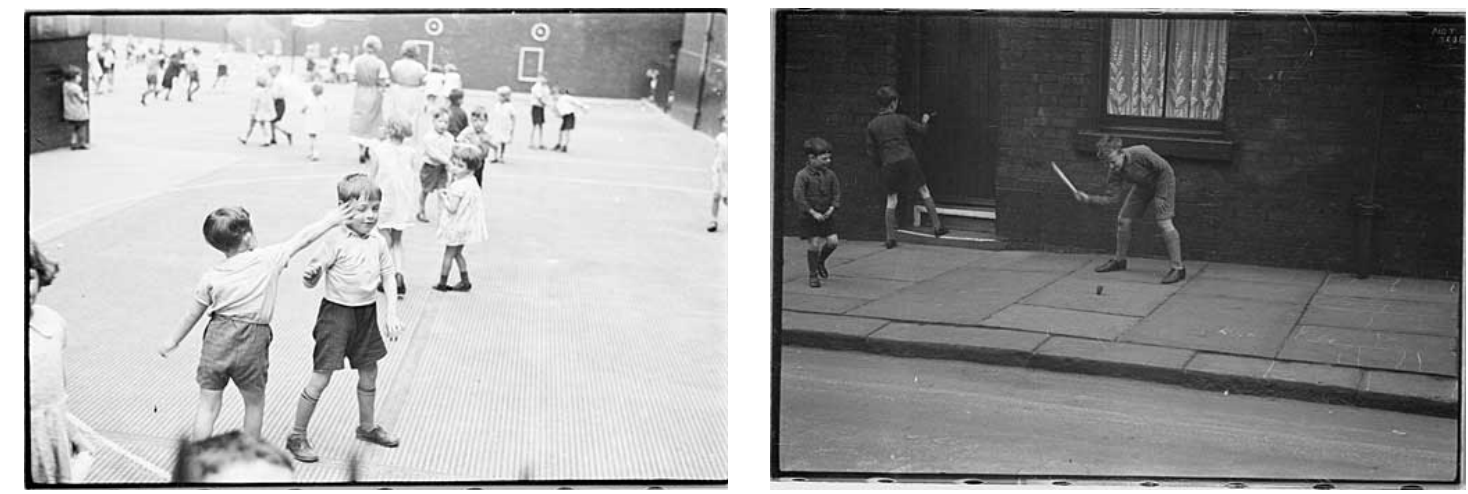

Fig. 13. Humphrey Spencer. Primavera de 1937, Bolton

Éste había vuelto completamente traumatizado por la experiencia como piloto de guerra y se había acogido a un programa gubernamental para cursar fotografía y bellas artes. Encontrar la alegría de vivir en la cotidianeidad de esa gente, afectada por la guerra como él, era una terapia inmejorable. Su obsesión por encontrar el placer en las pequeñas cosas cotidianas fue fundamental para descubrir la observación atenta y creativa posterior de los Smithsons. Esa actitud, de observar detalladamente la realidad y descubrir lo maravilloso detrás de lo aparentemente normal y/o vulgar, deprimente, olvidado, etc. es una actitud que los Smithsons pronto hicieron suya y, con ellos, las generaciones sucesivas.

"En arquitectura, la estética 'as found' ${ }^{2}$ era algo en lo que pensamos y a lo que dimos nombre a principios de los cincuenta, cuando conocimos a Nigel Henderson y vimos en sus fotografías un reconocimiento perceptivo de la realidad.

(...) la estética 'as found' fue una nueva forma de ver lo ordinario, una apertura en lo que se refiere a cómo las 'cosas' prosaicas podrían recargar de energía nuestra actividad creativa." (Robbins 1990, pp. 201-202) 
Sin embargo, la aceptación de la realidad, "tal cual" venía dada, no fue patrimonio exclusivo de Henderson. En 1951, año en que Golden Lane fue convocado, el filósofo social Leslie Paul publicaba su autobiografía bajo el título de Angry Young Men (Jóvenes Airados), nombre que sería empleado para denominar a una nueva generación de escritores ingleses cuyas novelas - como Hurry On Down (1953) de John Wain, Lucky Jim (1954) de Kingslay Amis o Look Back in Anger (1956) de John Osborne- compartieron el tema del descontento de los jóvenes estudiantes con la educación en el estado del bienestar, las estructuras de poder dominantes y con el declive de la cultura británica. El mundo del teatro, destacando la English Stage Company, pronto se hizo eco. Los personajes de estas obras eran jóvenes provenientes de las clases medias-bajas de la sociedad inglesa. Retrataban una realidad imperfecta, problemática, difícil, pero que luchaba por encontrar en sus resquicios un aire de felicidad.

El cine no se quedó atrás. En 1956 el National Film Theatre de Londres hizo una muestra de cortos producidos por jóvenes cineastas: Lindsay Anderson, Tony Richardson, Karel Reisz y Lorenza Mazzetti. Con el nombre de Free Cinema reclamaron cierta condición de método autónomo. Las tres películas proyectadas Together, O Dreamland y Momma Don't Allow - mostraban un enfoque definitivo en la vida cotidiana y la realidad de las grandes ciudades. Ese mismo año el escritor, y amigo de Henderson, Dylan Thomas suscribía el manifiesto del Free Cinema. El propio Paolozzi se convertió en protagonista de una de estas películas del Free Cinema. Together, de Lorenza Mazzetti, era una de estas películas que había encontrado en el East End londinense la fascinación por la vida en un entorno abatido. Lorenza, lo recuerda así ${ }^{3}$ :

"Cuando llegué al East End el paisaje me impactó, la atmósfera, y pensé que debía grabar a la gente que vivía en aquel mundo. Era como un escenario ya confeccionado. La dificultad de la gente para expresarse, comunicarse, me abrumó. Pero encontré su reserva y su genuina amabilidad extremadamente conmovedoras." (Mazzetti citada en Lichtenstein y Schregenberger 2001, p.234) 


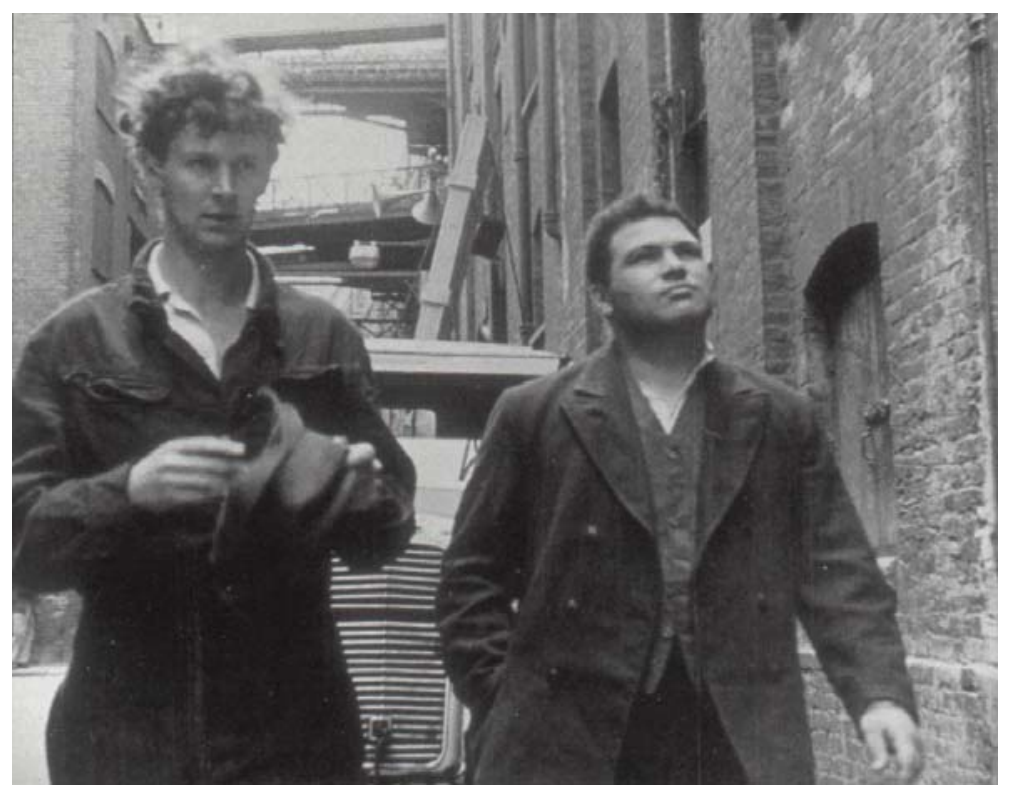

Fig. 14. Michael Andrews y Eduardo Paolozzi en Together. 1955

Pero hay algo todavía más revelador, las palabras de Karel Reisz, uno de los héroes del Free Cinema: "Se trataba de querer lo que tienes, en vez de salir a buscar lo que quieres." (Cinéma vérité defining the momento 1999)

\section{LA REALIDAD COMO NUEVO PARADIGMA}

Los Smithsons, así como Paolozzi y Henderson, fueron jóvenes de esa nueva generación descontenta con la realidad de posguerra y que reaccionaron contra el abismo existente entre la realidad idealizada por el mundo cultural conservador y la realidad que la guerra les había hecho vivir. Todos ellos pasarían por el East End londinense. Éste, sería un recordatorio permanente de la realidad que acabaron aceptando tal cual venía dada, con sus miserias y tragedias pero que, con algo de imaginación y energía creativa, podía ser transformada en lo más maravilloso del mundo.

Así lo entendió Nigel Henderson, como también el Free Cinema o los Jóvenes Airados. Henderson iría más allá y nos enseñó a disfrutar de las pequeñas cosas, descubriendo en cualquier acontecimiento la magia de la cotidianeidad. Las personas, en sus conductas cotidianas, serían el centro de la nueva realidad y fuente de inspiración continua.

Recordando los paseos "absolutamente increíbles" junto a Henderson, Alison Smithson lo describiría como el "encontrador de imágenes original", mientras que Peter Smithson 4 observó que "un paseo con Nigel es ver lo inanimado como animado, y entender esta extraña tarea de abrir... los ojos de otros para que veanpara establecer una relación de afecto entre la gente y los objetos." (Fathers of Pop, 1979). 
$\left[I^{2}\right]$ Innovación e Investigación en Arquitectura y Territorio. Revista Científica.

Paolozzi nos enseñaría a manipular la realidad de manera creativa mediante el uso del collage. Haciendo un paralelismo, los Smithsons entenderían que lo mismo que la técnica del collage hacía con sus materias primas, la arquitectura podía hacerlo con la realidad misma.

No es de extrañar, pues, el giro que sufrió el uso del fotomontaje en los Smithsons hacia una energía subjetiva más propia del collage. Golden Lane nos muestra el entorno del concurso tal cual es, con los restos de la tragedia, con sus ruinas y socavones, con la reminiscencia de los edificios que desaparecieron bajo las bombas. Sin embargo, aparecen las personas, las personas que tanto amaba Henderson, para dotar de una nueva vida a lo existente, para celebrar lo cotidiano y lo público. Ese es el primer objetivo en la arquitectura de los Smithsons ${ }^{5}$.

El collage permite superponer las tres capas de la nueva realidad en un solo dibujo: la realidad existente (representada por el entorno tal cual es), la intervención propuesta (representada por las líneas dibujadas sobre papel y pegado encima de la foto del emplazamiento) y la realidad creada (representada por las personas con nombre y apellidos recortadas de fotos reales y pegadas encima del resto). Sin embargo, lo que empieza siendo una mera técnica compositiva acaba convirtiéndose en una metodología proyectual. Paolozzi, influenciado por el Arte Marginal de Dubuffet y la filosofía de Sartre, enseña a los Smithsons que la intensidad creativa no está tanto en la construcción de un objeto sino en el proceso mismo de su construcción. El arte de Paolozzi, y de los Smithsons después, sería el arte de seleccionar, recortar y pegar al lado de. Esta técnica artística del collage se convirtió en una herramienta de conocimiento en la que se utilizaba la realidad como materia prima de trabajo lista para ser manipulada, interpretada y reinventada continuamente.

La realidad "tal cual" -imperfecta, devastada, trágica y, sobre todo, en absoluto idealizada como en décadas anteriores- por fin, estaba lista para convertirse en el nuevo paradigma.

1 Ver: MASSEY, Anne. The Independent Group: modernism and mass culture in Britain, 1945-59. New York: Manchester University Press, 1995.

2 "Tal cual ha sido encontrado".

3 Lorenza Mazzetti entrevistada por Christophe Dupin, Roma, Octubre 2000.

4 Entrevista de Reyner Banham a Alison y Peter Smithson.

5 Los Smithsons "...no ofrecen un estilo sino una serie de responsabilidades morales" Ver: BANHAM, Reyner. "Apropos the Smithson." New Statesman, 62. Septiembre, 1961. p. 317. 


\section{BIBLIOGRAFÍA}

1. WINTONICK, Peter. Cinéma vérité defining the moment [DVD]. Montréal / Québec: National Film Board of Canada, 1999.

2. COOPER, Julian. Fathers of pop. Londres: London Arts Council, 1979.

3. LICHTENSTEIN, Claude; SCHREGENBERGER, Thomas. (eds). As found : the discovery of the ordinary. Baden: Lars Müller, 2001.

4. ROBBINS, David. (ed). The Independent Group : postwar Britain and the aesthetics of plenty. Cambridge Mass.: MIT Press, 1990.

5. WALSH, Victoria; Gainsborough's House (eds.) Nigel Henderson: Parallel of Life and Art. London: Thames \& Hudson, 2001.

6. $\quad$ SMITHSON, Alison; SMITHSON, Peter. Urban Structuring: Studies of Alison \& Peter Smithson. Londres: Studio Vista; Nueva York: Reinhold, 1967.

7. RISSELADA, Max; VAN DEN HEUVEL, Dirk (eds). Team 10: 1953-81, in search of a utopia of the present. Rotterdam: NAi, 2005.

\section{REFERENCIA DE IMÁGENES}

(1) SMITHSON, Alison; SMITHSON, Peter. The charged void : architecture. Nueva York: Monacelli Press, 2001. p. 87.

(2) SAUNDERS, Ann; London County Council (eds.). The London County Council bomb damage maps, 1939-1945. Londres: London Topographical Society; London Metropolitan Archives, 2005. p. 30.

(3) RISSELADA, Max y VAN DEN HEUVEL, Dirk (eds.). Team 10: 1953-81, in search of a utopia of the present. Rotterdam: NAi, 2005. p. 30-33.

(4izq) LAMBERT, Phyllis (ed.). Mies in America. Montréal; Nueva York: Canadian Centre for Architecture; Whitney Museum of American Art; Harry N. Abrams Publishers, 2001. p. 110.

(4dcha) SMITHSON, Alison; SMITHSON, Peter. The charged void: architecture. Nueva York: Monacelli Press, 2001. p. 32.

(5) LAMBERT, Phyllis (ed.). Mies in America. Montréal; Nueva York: Canadian Centre for Architecture; Whitney Museum of American Art; Harry N. Abrams Publishers, 2001. p. 206-207.

(6) Ibíd., p. 28.

(7) Ibíd., p. 24.

(8izq) SMITHSON, Alison y SMITHSON, Peter. The charged void: urbanism. Nueva York: Monacelli Press, 2004. p. 25.

(8dcha) Ibíd., p. 21.

(9) WALSH, Victoria; Gainsborough's House (eds.). Nigel Henderson :

parallel of life and art. Londres: Thames \& Hudson, 2001. p. 120-121.

(10) LICHTENSTEIN, Claude; SCHREGENBERGER, Thomas (eds.). As found: the discovery of the ordinary. Baden, Suiza: Lars Müller, 2001. p. 69.

(11) WALSH, Victoria; Gainsborough's House (eds.). Nigel Henderson :

parallel of life and art. Londres: Thames \& Hudson, 2001. p. 48.

(12) Ibíd., 61, 62, 58. 
$\left[I^{2}\right]$ Innovación e Investigación en Arquitectura y Territorio. Revista Científica.

(13izq) Photography and Archives from the Mass Observation. <http://boltonworktown.co.uk/wp-content/uploads/1993.83.19.01.jpg > (13dcha) Ibíd.

<http://boltonworktown.co.uk/photograph/schoolchildren-in-asphaltedplayground>

(14) LICHTENSTEIN, Claude; SCHREGENBERGER, Thomas (eds.). As found : the discovery of the ordinary. Baden, Suiza: Lars Müller, 2001. p. 254. 